УАK 316.32

ББК 60.52

DOI 10.22394/1682-2358-2021-1-71-79

E.B. Kboroltseva, Candidate of Sciences (Philosopby), Docent at the Social Communications Department, Povolzhsky Institute of Management named after P.A. Stolypin, Branch of the Russian Presidential Academy of National Economy and Public Administration

A.V. Fedorova, Candidate of Sciences (Pbilosopby), Docent at the Social Communications Department, Povolzhsky Institute of Management named after P.A. Stolypin, Branch of the Russian Presidential Academy of National Economy and Public Administration

\section{COMMUNICATION ASPECTS OF PERSONALITY SELF-DETERMINATION IN THE ONLINE ENVIRONMENT}

Features of the modern state of society are analyzed: the lack of a civilizational, enlightened state, Christian culture norms leveling, life and online environment mixing. personality faces difficult questions of self-determination. It is proved that one of the most effective ways of self-determination is self-determination with the help of communicative practices of online environment.

Key words and word-combinations: communication, self-determination, online environment, labor, creativity, responsibility.
E.Б. ХорольцеВа, кандиат философских наук, дочент кафедрь сочиальньх коммуникачий Поволжского института упраљления имени П.А. Стольпина - филиала Российской академии народного хозяйства и государственной службы при Президенте РФ (email: borolceva-e@mail.ru)

A.B. Федорова, кандидат философских наук, дочент кафедрь сочиальньхх коммуникаций Поволжского института управления имени П.А. Стольтина - филиала Российской академии народного хозяйства и государственной службьг при Президенте РФ (email: anna_fedorova_76@list.ru)

\section{КОММУНИКАЦИОННЫЕ \\ АСПЕКТЫ \\ САМООПРЕАЕ АЕНИЯ

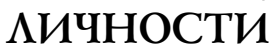 \\ В ОНААЙН-ПРОСТРАНСТВЕ}

Аннотащия. Проанализированы особенности современного состояния общества: отсутствие цивилизационного, просвещенного состояния, нивелирование норм христианской культуры, микширование жизненного и онлайн-пространства. Доказывается, что одним из эффективных способов самоопределения является самоопределение с помощью коммуникационных практик онлайн-пространства.

Ключевые слова и словосочетания: коммуникации, самоопределение, онлайн-пространство, труд, творчество, ответственность.

$\mathrm{H}$

а этапе актуамизации темы обратимся к более широкому контексту, опреАеляющему коммуникационные аспекты самоопределения мичности в онлайн-пространстве. Этим контекстом явцяются трансформации современного общества, 
современного в том смысле, что мы осмысливаем его в онлайн-режкиме и сосредотачиваем свое внимание на коммуникационных взаимодействиях «здесь-и-сейчас». Современные общественные трансформации опасны тем, что происходит разрушение Аействующих сощиацьных институтов и укоренившихся практик [1]. Основными особенностями функщионирования современного общества, на наш взгляА, является следующее: отсутствие просвещенного состояния общества, нивелирование ценностей, норм и традиций христианской культуры, неспособность извлекать смысмы из пережкитых событий, откцонение от цивицизационного развития, трасформационный характер и цифровизация процессов, взаимодействий и отношений [2] .

Что такое просвещенное состояние общества? В первую очередь его определяет просвещенное состояние самоопределившихся мичностей. В

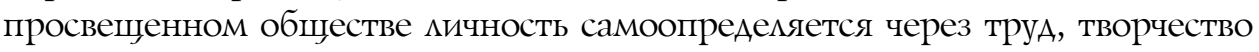
и живую мысль. Важно понимать, что самоопределение кичности - это непрерывные во времени и пространстве процессы, направленные на выстраивание отношения к себе, к Аругому и к миру. Самоопределение как сложный, рискованный, а порой и конфмиктный процесс становится актуальным как в череде рутинизированных практик, так и в трансформационных средах [3, с. 68-99]. В рутинных, ежедневно повторяющихся Аействиях и коммуникаџиях самоопределение мичности осуществляется автоматически, Ао-рефлексивно, в ресурсно-экономичном режкиме. В трансформационных средах процессы самоопределения необходимо запускать как можно чаще. Они становятся точками профессионацьного, мичностного роста и развития, помогают справиться с непрерывными изменениями. Коммуникационные самоопределения непосредственно связаны с формированием идентичности, нахождением своего места в жкизненном и онлайн-пространстве. Главные условия успешного коммуникационного самоопределения - внутреннее желание, честность, искренность по отношению к себе и ко всему происходящему, телеологические составмяющие (миссия, цели, задачи, кредо). Необходимо быть открытыми и гибкими (когнитивно и коммуникаџионно) по отношению к внешней и внутренней среде. Нужно отслеживать инфо-поля и информационные взаимодействия, своевременно реагировать на них. Необходимо обеспе-

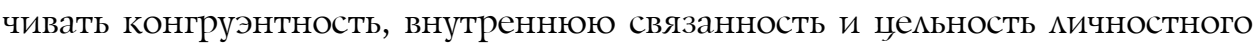
самоопределения в ониайн-пространстве. В этих условиях важно быть мужкественным и задавать себе неудобные вопросы: «я как кто сейчас говорю и действую?», «Амя чего я высказываю мнения, Ааю оџенки и формирую позиции?», «манипулирую ми я и Аля какого результата?».

Самоопределение - это нахождение себя и своего места в мире. Аичность определяет себя самостоятельно, поА вциянием внутренних интенций, но с помощью мира и других. В процессе самоопределения кичность проявцяет себя конфигуративно (пространственно), темпорацьно, содер-

72 Bulletin of the Volga Region Institute of Administration • 2021. Vol. 21. № 1 
жательно и коммуникационно. Каким образом можно самоопределиться через труд? Если задать этот вопрос современному человеку, то чаще всего можкно услышать ответ, что самоопределившийся - это человек, который знает, чего он хочет, ставит цели и достигает желаемых результатов, он социально успешен. Труд становится телеологичным, нагруженным целевыми установками кичности и сложным по степени связанности образующих его элементов. Возникает ситуация, когда выстраиваются в единую картину разнообразные цеми мичностей, подразделений, организации в целом и межкорганизационных взаимодействий. ГАавный акцент в труде современной мичности ставится не на элементах, а на типах связей межАУ элементами и коммуникаций, придающим им целостность. Внешняя коммуникационная связанность предполагает и внутреннюю связанность мичности: ее целевой картины, многочисленных интересов, ценностей и ценностных установок, мировоззрений, темперамента, согласованных и противоречивых выборов соџиальных действий и получаемых результатов, свобод и ответственностей, неминуемо сопровождающих послеАствия тех или иных выборов.

Уходят на второй план Аилеммы «качественное и быстрое», «жерт-

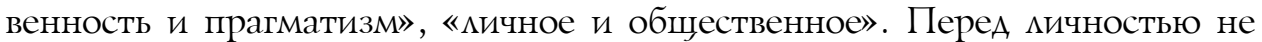
стоит выбор выполнить общественную работу или поработать на себя. Наиболее точно эту мысль раскрывает М. Мамардашвили. Эта дилемма просто не возникает в силу ее дихотомичности и вульгарности: «Просвещенное состояние человечества отвечает той стадии развития, когда труА осуществляется свободными проИЗводитеАями, вступаЮщими межАУ собой и с нанимателями в Аоговорные отношения» [4, с. 167]. Фицософ, несомненно, описывает идеацьную картину трудовых отношений, основанных на свободе нравственного выбора и умении взаимовыгодно Аоговариваться с работодателем. Но этот идеально-типический конструкт вполне реализуем в онлайн-пространстве. Ониайн-пространство по своим сущностным

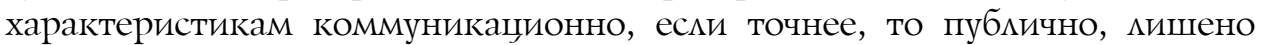
приватности. Эта сетевая пубцичность, в большей степени чем физическое пространство, способствует проявиению просвещенного состояния человека и общества. Основные причины состоят в том, что труА, степени свободы, которые мичность реализует в труде, ответственность, принятые и реализуемые решения, а также творчество в настоящее время становятся видимыми и транспарентными Аля огромного числа целевых аудиторий. Становятся видимыми, открытыми и уязвимыми результаты труда и Аля критики, агрессии, предвзятых ощенок и мнений. Ониайн-пространство значительно ускоряет процесс объективации результатов труда мичности, ускоряет проџессы самоопределения, повышает уровень творчества и степень ответственности, которую принимает на себя кичность. Онлайнпространство - это пространство высоких рисков, то есть соџиальных и коммуникационных действий в ситуации неопределенности, направлен- 
ных на достижение успеха, на получение выигрыша, но с сохраняющейся возможностью проигрыша, мгновенной потери всего. Неопределенность ониайн-пространства также высока, поскольку коммуникационный ответ на ваш труа и творчество может прийти весьма быстро, минуя географические границы организаций и целых государств. В этом смысле уже не получится трудиться, творить грандиозные проекты и оставаться при этом незаметным. Коммуникаџии онлайн-пространства мегче описать через образ импульса живой мысли. Именно они и составцяют ткань труда, творчества и коммуникаций онлайн-пространства. Ониайн-пространство конфигурировано функционирующими и изменяющимися узмами, сетями, каналами и рубильниками коммуникационных взаимодействий. Пубмичность коммуникационных взаимодействий накладывает дополнитель-

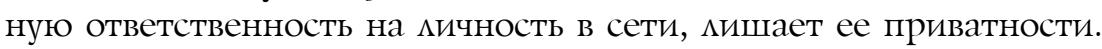

Аополнительная ответственность Аичности в виртуальной сети спровоцирована, на наш взгляд, целым рялом причин. Первая причина заключается в том, что ониайн-пространство как тип коммуникационной пубАичности состоит из глубоких ИнАивиАуалистов, которЫм весьма сложно в современных условиях объединяться в сообщества, Аелегировать права и свободы мидеру, повиноваться ему. Вторая причина состоит в том, чтобы не слиться с массами, не стать жертвами тотацьного контроля и манипумятивных воздействий со стороны государства и СМИ [5, с. 529-573] . Самоопределение кичности в онлайн-пространстве - сложный процесс топологического и темпорацьного определения собственной позиџии на основе ценностной вертикали. ЗаАача не из мегких - пройти межАу Сџилмой и ХарибАой: сохранить собственную индивидуальность и режимы аАжайıов, и вместе с тем создать или интегрироваться в сетевую общность Аля Аостижения результатов, получения эффектов от совместной деятельности и коммуникаџионного консенсуса. Высокие риски самоопределе-

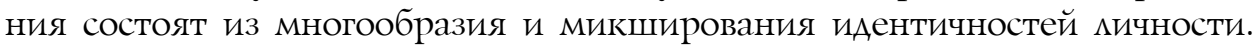
Аичность онлайн-пространства Аолжна находить в себе ресурсы и распознавать собственные идентичности, переключаться с одной на Аругую, в большей степени соответствующую ситуации. Онцайн-пространство и соответствующие ему коммуникаџии не дают кичности передышки: они непрерывны, они Алятся и Аһятся, кажАый раз воспроизводя новую ацьтернативную реальность самоопределения кичности. Онлайн-пространству присуща открытость, плюрализм и опосредованность [6, с. 25-35]. Коммуникации онцайн-пространства - косвенные и опосредованные, способные быстро воспроизводиться и изменяться поА вАиянием внутренней и внешней среды, снабжены многочисленными узмами социальных связей, являющихся основаниями пространственного плюрацизма. В онлайн-пространстве присутствует и темпоральный плюрацизм, состоящий из различных оџенок и позиций по отношению к событиям прошлого, настоящего и булушего. Темпорацьность ониайн-пространства опирается на разрыв

\section{Bulletin of the Volga Region Institute of Administration • 2021. Vol. 21. № 1}


событийного ряда, когда можно прокомментировать, оценить или выложкить собственный проект в удобное время.

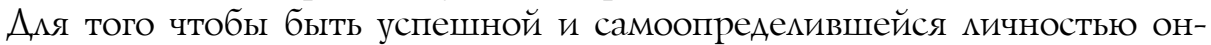
майн-пространства, необходимо также обладать открытостью, опосредованностью и плюрализмом в мировоззрении. Аичность должна быть восприимчива к непрерывным изменениям внутренней и внешней среды онлайн-пространства, к собственным контурам самоопределения, терпима к условиям неопределенности, турбулентности и хаоса. Она должна отмичаться гибкостью и ирраџиональностью в случае необходимости, хорошо знать и уметь управмять собственными спонтанными импумьсивными проявлениями. С Аругой стороны, мичность онлайн-пространства - это мыслящая и творящая кичность, интегрированная в онлайн-сообщества и сообщества физического пространства на основе соџиальных действий, ромей, позищий и статусов. Раскрытию мичностных проявлений способствует творчество. Социологический энциклопедический словарь под редакцией Г.В. Осипова определяет творчество как «деятельность, отмеченную неповторимостью, оригинальностью и общественно-исторической уникальностью [7, с. 355]. Аичность самоопредемяется и интегрируется через практики творчества в онлайн-пространстве. С Аругой стороны, мы стацкиваемся с парадоксальными проявлениями мичностного и профессионального самоопределения. ОАним из форм такого рода проявмений явмяется скрытая, или отчужденная, субъектность. Феномен отчужденной субъектности можно охарактеризовать как Аекларацию выборочной субъектной значимости для Аругого. Поскольку коммуникационные взаимодействия опосредованы соџиальной сетью, то мичность может выбирать различные аспекты собственной субъектности Аля размещения в сетевом пространстве и определять уровни и формы возможных конфигураций. Они могут сколь угодно Аолго простираться из настоящего в прошлое и будущее.

Триада «труд - творчество - живая мысль» представмяет собой конфигурацию просвещенного состояния мичности, которую необходимо дополнить темпоральными характеристиками. Темпоральные характеристики - более сложные, чем пространственное расположение элементов, но тем не менее именно они формируют вертикаль профессионального и мичностного самоопределения в коммуникационных полях. Темпоральность ониайн-пространства формируется отношением к настоящему, прошлому и будушему. Настояшее раскрывается в творческом акте, свободном труде и договорных отношениях, коммуникативных действиях. Ретроспектива открывается в осмыслении событий прошлого, а перспектива создается разнообразными цемями и задачами, пробрасываемыми в будущее. М. Мамардашвици отмечает сложность темпоральности и живой мысли цичности в ней: «Мы живем в пространстве, в котором накоплена чудовищная масса отходов производства мысли и языка. Пространство это замусорено побочными, вторичными продуктами нормальной мыслитель- 
ной и духовной деятельности, мифологизированными их осколками. Поэтому даже если мы хотим мыслить, когда есть позыв, побуждение мысли, у нас ничего не получается. Что-то уже нарушено в языке, в его основании» [4, с. 165]. Это, на наш взгляА, явцяется основной причиной, согласно которой невозможно полноценно осмыслить собственное прошлое, извлечь необходимые дмя жкизни смыслы и выстроить перспективы дальнейшего развития. Временные модусы оказываются слабо связанными смысловыми блоками межАу собой. В этом аспекте мы похожи на африканское пмемя, чмены которого, засыпая, думают, что они умирают, а просыпаясь каждое утро, знакомятся Аруг с Аругом заново.

Темпоральная рассогласованность усугубилась благодаря стремительному развитию технологической сферы и принудительному характеру проявления онлайн-пространства. Оно благополучно существовало в форме фоновых практик жизненного пространства современной кичности и скужило в основном Аля отвлечения и развлечения, кичного и профессионального перформанса, демонстрации статусности. Онцайн-пространство интенџиально провоцирует акторов коммуникаџий на игры с идеальными представлениями о жизненном пространстве и явцяло собой некоторую утопию жкизненного пространства человека. Утопию, в которой нет места разочарованиям, тревогам, отчаянию, беспокойству, неуспеху, старости и смерти, а выбор человека может быть сколь угодно бесконечным. Современный человек может выбирать все, что только возможно выбрать. Открывающиеся «возможности» - многообразны и доступны, заманчивы и мегко реализуемы. Онлайн-пространству присущ фцер гедонизма, что, конечно, противоречит нормам и традиџиям христианской культуры, составмяющей ткань нашей общественной жизни. Нормам христианской культура чужды идеи гедонизма, весьма распространенные в рамках нашего общества установки «живем один раз», поэтому «нужно взять от жизни все, немедленно и быстро». Онлайн-пространство и коммуникации, соответствующие ему, нивелируют жертвенность, соборность, экзистенциаль-

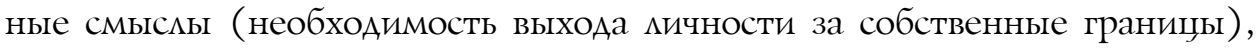
идеи вечности и Ауховности.

Определенные ценности и нормы христианской культуры частично сохранены в жиизненном физическом пространстве кичности. Но даже в жизненном пространстве они преАставцяют собой скорее цакуны смыслов, пустоты, стремящиеся к заполненности. Что имеется в виАу? Христианская культура активно проявляет себя в рамках формального соответствия религиозным, морально-нравственным и этическим устоявшимся практикам. Но эти практики оказываются мишены содержательной наполненности, активного самоопределения цичности в практиках христианской жизни. Нам по-прежкнему остаются присущи теплохладность, или, как сейчас принято говорить, толерантность (нейтрацьное отношение к Аругому), аспатильность (равнодушие к месту, пространству, в котором мы

76 Bulletin of the Volga Region Institute of Administration • 2021. Vol. 21. № 1 
живем), эгоизм (доминанта нашей современной жизни), подменяющийся индивидуализмом, заботой о себе.

Априори признается доминирующая роль жизненного пространства. Если быть точнее, то жизненное пространство «отвоевывает и присваивает» себе эту роль, выдерживая многочисленные конфликты с онцайнпространством, вытесняя его в инструментальную сферу [8, с. 60-118] . Жизненное пространство не признает игр, кжи и миџемерия, сравнений с идеалами и выстраивание могик жизненного пространства в соответствии с идеальными образцами и практиками. «Не признает» в том смысле, что если вы пожелаете заняться этими весьма неперспективными практиками, то вскоре будете разоблачены или превратитесь в циников. И та, и другая стратегия мишена будущего. Реальное жизненное пространство масштабнее и сложнее мюбых утопий и антиутопий; оно связаннее и насыщеннее по собственной событийности и, несомненно, намного напряженнее онлайн виртуального пространства. Полагаем, что именно поэтому нерационально, может быть интуитивно, современный человек наиболее сокровенные (субъективно окрашенные) аспекты труда и творчества цокацизует в жизненном пространстве. Каким образом формируется и присваивается Аичностью свободный труд, основанный на творчестве и договоренностях? Аело в том, что на протяжении жизни человек изменяет ведущую деятельность несколько раз. В раннем детском возрасте ведущей деятельностью является общение. На смену ему приходит игра, впоследствии ее сменяет учебная деятельность, затем - профессиональная. Завершается жизнь человека опять общением. Круг замкнулся: общение - игра - обучение - работа - обшение. Что такое ведущая деятельность? Это такой вид Аеятельности, которой человек на том или ином этапе жизненного пути посвящает себя целиком, 90\% своего времени и сил он отдает этому занятию. Ведущая деятельность того или иного жизненного этапа способствует становлению человека, помогает ему перерастать себя.

М. Мамардашвили в своих трудах часто упоминает о том, что жкизнь чемовека - это усилие во времени. Это цивицизованное понимание жизни, от которого мы очень далеки, как далеки от цивилизованного развития общества в целом. Что такое цивилизованное развитие? На наш взгляд, оно вкцючает следующие необходимые эмементы: приобретение знаний Амя активного использования, критичное восприятие происходящих событий, а также событий прошиого и прогнозов на будушее, принятие ответственности за собственную жкизн, четкое позиционирование в общественной жизни и понимание гранищ собственных прав и свобод, а также признание прав и свобод Аругих, готовность к самоограничению Аля совместной интеграции, готовность отстаивать собственные права и свободы и нести ответственность за последствия принятых и реализуемых решений. Самоопределение кичности выстраивается на основе знания и уважения к праву и граниџам, которые очерчивает это право. Аругим аспектом са- 
моопределения мичности является отношение к частному, приватному, к частным правам и свободам, к частной собственности. Огромное влияние

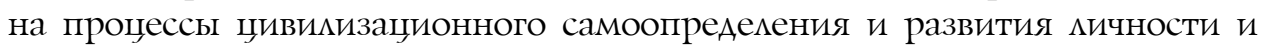
современного общества оказывает коммунацьная куцьтура с соответствующими ей нормами и коммуникационными взаимодействиями.

Коммунальная культура опирается на стремление все делать вместе, комлективно отвечать за сделанное, отсутствие частного и самого понимания того, что частное, может быть, формирует и подАерживает общественное сознание. Управление мичностями и коммуникациями осуществцяется на основе чувства вины переА значимыми Аругими, как некоторый ответ на реакцию среды. Следствием реализации норм коммунальной культуры является развитие среды. Мы привыкли создавать и развивать Аругих, вкладывать ресурсы во внешних мюдей, внешние коммуникации и обстоятельства. С одной стороны, этот тренд можно рассматривать как положительный с точки зрения расширения ониайн-пространства и оптимизаџии процессов самоопределения мичности в этом пространстве. С Аругой стороны, это пространство, среда несут фрейм принудительности, навязан-

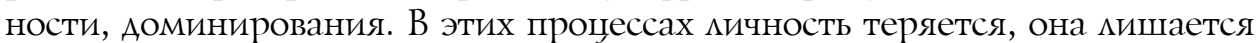
свободы воли и уникальности в соџиальных и коммуникационных проявлениях. Коммунальная культура прекрасно коррелирует с унифицированностью онлайн-пространства, которая достигается благодаря слепому администрированию. Аичности ониайн-пространства часто не понимают, почему их постигли те или иные санкщии (занижение числа подписчиков; мишение возможности несколько Аней пользоваться сетевыми ресурсами). Осмысление причин санкщий обычно способствует трансформащии собственных практик в соответствии с административными запросами.

Подведем итог нашим умозаключениям. Во-первых, необходимо признать, что развитие технологической сферы и онлайн-пространства не-

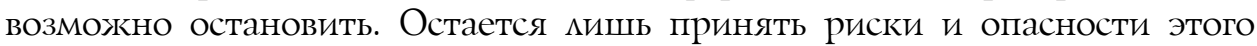
развития, по возможности управцять ими, совершать усилие во времени, формировать европейский тип мичности и приверженность цивилизационному развитию.

Во-вторых, мы оказались не готовы к такому развитию событий, к тому, что онцайн-пространство и онлайн-коммуникации настолько стремительно из фоновых практик трансформируются в практики переАнего, точнее, передового плана. Мы не знаем, каким образом выстраивать мичную и профессиональную жкизнь в границах ониайн-пространства и что, собственно, определяет эти границы? Мы толыко формируем этот опыт коммуникационных взаимодействий и самоопределений.

В-третьих, современный человек еще долго будет существовать и выстраивать коммуникации на границе Авух миров, Авух пространств жизненного и онлайн-пространства [9, с. 33]. Важно понимать, что эти пространства находятся в состоянии борьбы за человека, его внимание,

78 Bulletin of the Volga Region Institute of Administration • 2021. Vol. 21. № 1 
жизненные силы, время и ценности. Именно в такой последовательности, поскольку внимание определяет качество и количество того времени, которое мы затрачиваем на событийность, а также силы, которые отдаем онлайн-пространству. Время, в свою очередь детерминирует ценности, так как то, на что мы затрачиваем больше времени и сил, становится более ценным, важным дия нас соразмерно временнОму вкладу.

В-четвертых, современному человеку необходимо научиться выходить из конфликта двух пространств: договариваться с собой, заключать соглашения с совестью. Звучит несколько нравоучительно, но сложность этого конфликта состоит в том, что он преАставмяет собой конфцикт ценностей и приоритетов. Чтобы выйти из этого конфликта, необходимо расставить приоритеты и придержкиваться сделанного выбора [10, с. 320-360]. Но и это еще Аалеко не все. Чтобы совершить выбор, необходимо задавать себе вопрос «кто я?» и с этим «неудобным» вопросом действовать и коммуницировать.

\section{Библиографический список}

1. Фролова С.М. Институциализация и рискогенность повседневной жизни общества / под ред. В.Б. Устьянцева. Саратов, 2013. 1989

3. Рязанов A.B. Российский социум: динамика трансформаций. Саратов, 2020.

4. Мамардашвили М.К. Третье состояние // Сознание и цивилизация. СПб., 1989.

5. Эко У. Полный назад! «Горячие войны» и популизм в СМИ. М., 2007.

6. Трубина Е. Публика: краткий очерк понятия // Публичная сфера: теория, методология, кейс стади / под ред. Е.Р. Ярской-Смирновой, П.В. Романова. М., 2013.

7. Социологический энциклопедический словарь / на русском, английском, немецком, французском и чешском языках; ред.-корр. Г.В. Осипов. М., 1998.

8. Зазаева Н.Б., Федюнина С.М., Морохова Е.И. [и др.] Управление коммуникациями в эпоху цифровизации / под ред. Н.Б. Зазаевой. Саратов, 2020.

9. Наумов С.Ю., Журавлев П.В., Шеховщев А.Ю., Федорова А.В. Риски в коммуникативном пространстве социума. Саратов, 2004.

10. Черниговская T.B. Чеширская улыбка кота Шредингера: язык и сознание. М., 2017. 